\title{
Glycine-Stabilized Zinc Gluconate Has Similar Bioavailability than Zinc Sulfate In a Zinc Fortified Probiotic Food
}

\author{
F. Tesán ${ }^{1, *}$, F. Hernández ${ }^{1}$, H. Torti ${ }^{1}$, F. Massot ${ }^{1}$, M. Huarte ${ }^{1}$, E. Rubín de Celis ${ }^{1}$, M.L. Arcos Barreiro ${ }^{3}$, \\ R. Weill ${ }^{4}$, G. Cremaschi ${ }^{2,3}$, J. Boccio ${ }^{1}$ and M.J. Salgueiro ${ }^{1,2}$
}

${ }^{I}$ Stable Isotope Laboratory Applied to Biology and Medicine; ${ }^{2}$ Radioisotope Laboratory, Physics Department, School of Pharmacy and Biochemistry, University of Buenos Aires, Buenos Aires, Argentina; ${ }^{3}$ CEFYBO, CONICET, Argentina; ${ }^{4}$ Research and Development Department, Danone Argentina SA, Buenos Aires, Argentina

\begin{abstract}
Objective: In this study, we evaluated zinc gluconate stabilized with glycine (GZ) and sulfate (SZ) in fermented milk as vehicle. Zinc bioavailability was evaluated in an animal model (Sprague Dawley rats) for both zinc sources in the vehicle with a probiotic (Lactobacillus casei DN114001).

Results: For growth parameters, higher weight gain and femur weight values were observed when probiotic and zinc were provided together, independent of the source (weight gain: SZ 81.4g $\pm 4.0 \mathrm{~g}$; GZ 81.8g $\pm 4.0 \mathrm{~g}$ and $70.2 \mathrm{~g} \pm 12.5 \mathrm{~g}$ without the probiotic; femur weight: SZ $0.51 \mathrm{~g} \pm 0.05 \mathrm{~g}$; GZ $0.52 \mathrm{~g} \pm 0.05 \mathrm{~g}$ and $0.42 \mathrm{~g} \pm 0.03 \mathrm{~g}$ without the probiotic). Femur zinc content was higher for zinc gluconate stabilized with glycine in the presence of the probiotic $(97.04 \mathrm{ppm} \pm 8.40 \mathrm{ppm})$, and the results were similar for zinc sulfate with or without probiotic $(84.51 \mathrm{ppm} \pm 2.44 \mathrm{ppm}$ and $84.94 \mathrm{ppm} \pm 2.28 \mathrm{ppm}$, respectively). Serum antioxidant capacity and immune cellular response were also evaluated by using free radical scavenging assays and a $\mathrm{T}$ cell proliferation assay respectively. The free radical scavenging assay showed a tendency to increase with zinc provision, and the highest proliferation index was observed for glycine-stabilized zinc gluconate and the probiotic.
\end{abstract}

Conclusion: The results indicate that the combination of zinc (as glycine-stabilized zinc gluconate) and a probiotic may be beneficial for the evaluated parameters.

Keywords: Bioavailability, zinc, probiotic, food fortification, rats.

\section{INTRODUCTION}

Zinc is an essential component of a large number of enzymes. It also plays a central role in cellular growth and differentiation for tissues with rapid turnover, including those of the immune system and the gastrointestinal tract [1-4]. The most important of the negative effects of zinc deficiency involve impaired immune function, subnormal growth and gonadal development. Zinc supplementation has been used to prevent and treat childhood diseases like acute diarrhea, gastroenteritis, pneumonia and malaria [5-7], providing solid evidence of the high importance of this micronutrient. Recent studies have also demonstrated zinc's protective effect against oxidative stress and DNA damage [8-11]. These studies have been performed both in vivo and in vitro, where it was demonstrated that zinc is needed for some DNA binding proteins, such as $\mathrm{p} 53$, to fulfill their regulatory function. A mineral deficiency, and particularly zinc deficiency, even mild, may potentially cause DNA breakage (similar to that caused by ionizing radiation or chemicals) and oxidative stress, resulting in a possible increase in cancer risk [12]. However, the extent of zinc deficiency worldwide is not well

*Address correspondence to this author at the Radioisotope laboratory, UBA. Junin 956 piso bajo, 1113, Ciudad de Buenos Aires, Argentina; Tel/Fax: (+5411) 4964-8202, ext 33; E-mail: ftesan @ffyb.uba.ar documented. All population age groups are at risk of zinc deficiency, but infants and young children are probably the most vulnerable. The lack of reliable, widely accepted, and adequately sensitive indicators of zinc status has resulted in uncertainty about the global prevalence of zinc deficiency. Using estimates of zinc intake and bioavailability derived from FAO's food balance data, about $20 \%$ of the world's population could be at risk of zinc deficiency. Therefore, since zinc status remains an important issue for human health, it is essential to develop and execute efficient and cost-effective strategies to overcome zinc deficiency. On 2009, the IZiNCG (International Zinc Nutrition Consultative Group) Steering Committee reexamined the latest strategies to control zinc deficiency and to enhance zinc nutrition [13]. One of the most recognized strategies for reducing zinc deficiency is food fortification, yet the beneficial effects claimed by fortified foods need scientific validation. For such a validation, bioavailability studies should be performed, and different nutritional matrixes should be compared and evaluated in addition to the mineral source used. These studies should be complemented with other studies which demonstrate that the fortified food properties have not been negatively altered in any way after the fortification procedures [14].

Fermented dairy products with added probiotics are interesting targets for zinc fortification. Probiotics are 
well known for their positive impact on intestinal health, stimulation of immune response and protection against pathogens (S. typhimurium, S. aureus, E. coli, C. perfigens or C. difficile) [15-18]. Since both zinc and probiotics have beneficial effects on humans' nutritional and immunological status, their effect taken together could be amplified, resulting, for example, in improved mineral absorption or a higher cellular immune response. For this reason, it is interesting to evaluate the potential nutritional impact of a functional food containing both zinc and probiotics. Some works focused on this combination as a therapeutic option for diarrhea or even HIV [7, 19] and others on its effect on antioxidant capacity of blood, zinc serum levels and intestinal microflora [20]. However for diarrhea and HIV, zinc and probiotics actions have been studied but mostly on separate trials [21-25].

The aim of this work was to determine the bioavailability of zinc in fermented milk as a vehicle with the addition of a probiotic (Lactobacillus casei). The zinc sources under study were zinc sulfate as a reference standard and zinc gluconate stabilized with glycine. Further, the effect on immunological response and the antioxidant properties of the fortified food were evaluated.

\section{MATERIALS AND METHODOLOGY}

\section{Bioavailability Assay}

\section{Animals}

All animal experiments were performed in accordance with the "Guide for the Care and Use of Laboratory Animals, U.S. National Research Council, 1993". Ninety 18day-old Sprague Dawley female rats (School of Agronomy and Veterinary, University of Buenos Aires, Argentina) were randomly divided into ten groups and were housed in stainless steel cages with a grated floor of the same material. Water and the diet corresponding to the treatment received (see treatments below) were provided ad libitum. Food intake was noted daily. Animals were kept in a humidityand temperature-controlled environment with a $12 \mathrm{~h}$ light$12 \mathrm{~h}$ darkness cycle.

\section{Diets}

Diets for bioavailability assay were prepared based on a protocol previously described by others [26-29] and used in our laboratory $[30,31]$. Briefly, diets were prepared according to AIN-93G but modified in their zinc content and provision [32]. Zinc was provided either as zinc sulfate (ZnSO4.7H20, JT BAKER, Mexico) or zinc gluconate stabilized with glycine (Lipotech, Argentina) in three different levels: $6 \mathrm{ppm}, 18 \mathrm{ppm}$ and $35 \mathrm{ppm}$. The zinc content of the diets was determined by atomic absorption spectrophotometry.

\section{Treatments}

Animals were divided into ten groups receiving the following treatments: Groups SZI, SZII and SZIII were fed diets containing zinc sulfate at $6 \mathrm{ppm}, 18 \mathrm{ppm}$ and $35 \mathrm{ppm}$, respectively. Groups GZI, GZII and GZIII were fed diets containing zinc gluconate stabilized with glycine at $6 \mathrm{ppm}$,
$18 \mathrm{ppm}$ and $35 \mathrm{ppm}$, respectively. For all six groups, the corresponding zinc source was added in the vehicle of fermented milk ( $10 \%$ of final diet) containing a probiotic (Lactobacillus casei DN114001, >1 E ${ }^{08} \mathrm{ufc} / \mathrm{gr}$ ). Groups CI, $\mathrm{CII}$ and CIII were fed diets containing zinc sulfate at $6 \mathrm{ppm}$, $18 \mathrm{ppm}$ and $35 \mathrm{ppm}$, respectively, provided in the same vehicle without probiotic. The $10^{\text {th }}$ group was fed with a diet based on AIN -93G without zinc addition (2ppm) [31].

Treatments lasted four weeks and consisted of feeding animals the corresponding diet. Food intake was noted daily and body weight was recorded twice a week. At the end of the treatments, animals were euthanized for sample collection.

\section{Sample Collection and Processing}

Intestinal lymph nodes and serum collected from blood samples were immediately processed as described below for the proliferation assay and for the antioxidant capacity assay, respectively.

Femurs were also extracted and kept frozen at $-70^{\circ} \mathrm{C}$ until they were analyzed for zinc content by atomic absorption spectrophotometry, as previously described [33].

\section{Mathematical Analysis}

Relative bioavailability was obtained as previously described $[30,31]$. Briefly, the ratio among significant parameters of the nonlinear fits of weight gain and femur weight and the linear fit of femur zinc content, all as a function of dietary zinc concentration, were obtained for the zinc source under study and for the reference standard. Comparison of these ratios yielded the bioavailability results. Relative bioavailability by means of weight gain and femur weight was calculated using $\mathrm{Y}_{\max }$ and $\mathrm{Y}_{\max } / \mathrm{t} 1 / 2$ ratio for both zinc sources. Similarly, relative bioavailability using femur zinc content was calculated using the slope ratio for both zinc sources.

\section{Proliferation Assay}

\section{Groups}

Animals were evaluated from groups fed diets containing zinc sulfate and glycine-stabilized zinc gluconate at level of $35 \mathrm{ppm}$, provided in the probiotic (SZIII and GZIII). For comparative purposes, a third group that had been fed a balanced diet (Ganave alimentos balanceados, Argentina) was included.

\section{Lymphoid Cell Suspension from Lymph Nodes}

The cell culture medium used was RPMI $1640\left(\mathrm{Gibco}^{\mathrm{TM}}\right.$, Invitrogen, Carlsbad, USA). Briefly, lymphoid organs were aseptically removed and filtered through a $1-\mathrm{mm}$ metal mesh, and the resulting cell suspensions were filtered through a $10-\mu \mathrm{m}$ nylon mesh. After three washes in RPMI 1640 medium, cells were resuspended in RPMI 1640, supplemented with $10 \%$ batch-tested, non stimulatory fetal bovine serum (Gibco ${ }^{\mathrm{TM}}$, Invitrogen, Carlsbad, USA), $2 \mathrm{mM}$ glutamine (Gibco ${ }^{\mathrm{TM}}$, Invitrogen, Carlsbad, USA), $100 \mathrm{U} / \mathrm{ml}$ penicillin (Gibco ${ }^{\mathrm{TM}}$, Invitrogen, Carlsbad, USA), and 100 $\mathrm{g} / \mathrm{ml}$ streptomycin (Gibco ${ }^{\mathrm{TM}}$, Invitrogen, Carlsbad, USA). 
Cell viability was estimated according to the Trypan blue exclusion criteria at over $90 \%$.

\section{Mitogen Assay}

Cells $\left(1.5 \times 10^{6}\right.$ cells $\left./ \mathrm{ml}\right)$ were seeded at a final volume of $0.2 \mathrm{ml}$ in $96-$-well flat-bottom microtiter plates ( $\mathrm{Nunc}^{\mathrm{TM}}$, USA) in triplicate aliquots. The T-cell-selective mitogen used was Concanavalin A (Con A; Sigma Chemical Co., USA), added at $1 \mu \mathrm{g} / \mathrm{ml}$ to the microcultures. Cells were cultured at $37^{\circ} \mathrm{C}$ in a $5 \% \mathrm{CO}_{2}$ atmosphere for different periods. Cells stimulated with the mitogen displayed the expected kinetic of proliferation, with a peak on day three of the culture. Proliferation was measured by adding $0.75 \mu \mathrm{Ci}$ $\left[{ }^{3} \mathrm{H}\right]$-thymidine $\left(\left[{ }^{3} \mathrm{H}\right] \mathrm{TdR}\right.$, Perkin Elmer precisely, Boston, MA, USA, $20 \mathrm{Ci} / \mathrm{mmol}$ ) for the last 18 -h period of culture. Thymidine incorporation was measured by scintillation counting after retention over GF/C glass-fiber filters (Whatman International Ltd, Maidstone, UK) of the acid-insoluble macromolecular fraction. The activity (disintegrations per minute, dpm) in basal cultures was subtracted from the activity (dpm) in stimulated cultures. The proliferation index was calculated as a ratio of proliferations observed with mitogen to basal proliferation. For comparative purposes, a group fed a balanced diet of $209 \mathrm{ppm}$ of zinc (Ganave alimentos balanceados, Argentina) was included.

\section{Antioxidant Power Assay}

Both experiments described below were performed in triplicate, and the temperature was kept at $20^{\circ} \mathrm{C}$. The results were expressed in ascorbic acid equivalent units (AEU) corresponding to the ascorbic acid concentration necessary to achieve the same scavenging velocity as the sample evaluated. Sodium ascorbate (JT BAKER, México) solutions between 10 and $100 \mu \mathrm{mol} / \mathrm{L}$ in buffer phosphate saline $\mathrm{pH} 7.6$ were simultaneously prepared. The balanced-diet group was also included as in the mitogen assay.

\section{DPPH Assay}

The antioxidant status of serum was determined spectrophotometrically through the Brand-Williams method [34] with modifications, using the stable free radical 2,2diphenyl-1-picrylhydrazyl (DPPH, Sigma Chemical Co., USA). DPPH consumption was calculated as a $\Delta$ absorbance from DPPH in the absence and presence of rat serum. Absorbance at $515 \mathrm{~nm}$ was measured by a spectrophotometer (Shimadzu-Double beam, UV-visible 210A, Japan) $30 \mathrm{~min}$ after starting the reaction.

\section{TEMPO Scavenging Assay}

The ascorbic acid serum status was determined by electron spin resonance (ESR) spectroscopy (X band ESR Spectrometer Bruker ECS 106, German) as described elsewhere [35]. TEMPO (2,2,5,5-tetramethyl-4-piperidin-1-oxyl) (Sigma Chemical Co., USA) stock solution $(6.3 \mathrm{mmol} / \mathrm{L})$ was prepared with $96 \%$ ethanol (Laboratorios Cicarelli, Argentina) and stored at $4{ }^{\circ} \mathrm{C}$ until needed. In total, $4 \mu 1$ of TEMPO solution was added to $96 \mu \mathrm{l}$ of serum sample to achieve a TEMPO final concentration of $256 \mu \mathrm{m} / 1$. Each sample was put in a capillary that was placed in an ESR quartz tube inside the ESR cavity. ESR spectra between 3 min and 9 min were recorded at $20^{\circ} \mathrm{C}$. The standard spectrometer settings for TEMPO were the following: center field $3480 \mathrm{G}$. sweep width $80 \mathrm{G}$. microwave power $5.04 \mathrm{mWatt}$; microwave frequency $9.73 \mathrm{GHz}$; conversion time $2.56 \mathrm{~ms}$; time constant $2.56 \mathrm{~ms}$; modulation amplitude $0.107 \mathrm{G}$; modulation frequency $50 \mathrm{kHz}$; gain 1.12 x 104; resolution 1024 points. All spectra were the accumulation of 10 scans. TEMPO signal intensity was measured as the total height of the low field peak $(h+1)$ in the first derivated spectrum of the $14 \mathrm{~N}$ triplet of the TEMPO nitroxide.

\section{Statistical Analysis}

All data were analyzed using a computer statistical program (Graph Pad PRISM ${ }^{\circledR}$, Version 3.00, 1999, GraphPad Software Inc., San Diego CA, USA). Data from all groups included in the bioavailability, proliferation and antioxidant power assays were compared via a two-way variance analysis (ANOVA). A post-hoc Tukey's test was carried out in each case, if necessary, to find the differences between groups. The level of significance for all tests was $\mathrm{P}<0.05$ [36].

\section{RESULTS}

\section{Bioavailability}

Weight gain $(\mathrm{g})$ for groups that were fed diets containing zinc sulfate or glycine-stabilized zinc gluconate in the probiotic was similar (SZI $62.1 \pm 5.3^{\mathrm{a}}$, SZII $72.3 \pm 4.3^{\mathrm{a}}$, SZIII $81.4 \pm 4.0^{\mathrm{ab}}$, GZI $68.3 \pm 4.2^{\mathrm{a}}$, GZII $77.8 \pm 3.0^{\mathrm{a}}$, GZIII $\left.81.8 \pm 4.0^{\mathrm{a}}\right)$, but was significantly different $(p<0.05)$ from that of groups that received only zinc sulfate (CZI $42.7 \pm 6.8^{\mathrm{b}}$, CZII $70.6 \pm 8.2^{\mathrm{b}}$, CZIII $70.2 \pm 12.5^{\mathrm{b}}$ ), considering each level of zinc added (for each level with the same provision of zinc, different superscripts mean that they are significantly different). Dose response curves for weight gain as a function of dietary zinc obtained from nonlinear fits are shown in Fig. (1).

Relevant nonlinear fit parameters, such as Ymax, which is the maximum response reached, T1/2, which is the dietary zinc concentration needed to achieve half of the maximum response, and the correlation coefficient of the adjustment are shown in Table 1. Relative bioavailability calculations took into account $Y$ max and efficiency as a ratio between $Y$ $\max$ and t1/2. Those values, as well as an average relative bioavailability, are also shown in Table $\mathbf{1}$.

Similarly, femur weight (g) was comparable for groups that were fed diets containing zinc sulfate or zinc gluconate stabilized with glycine in the probiotic (SZI $0.44 \pm 0.03^{\mathrm{a}}$, SZII $0.50 \pm 0.03^{\mathrm{a}}, \quad$ SZIII $0.51 \pm 0.05^{\mathrm{ab}}, \quad$ GZI $0.48 \pm 0.03^{\mathrm{a}}$, GZII $0.51 \pm 0.03^{\mathrm{a}}$, GZIII $0.52 \pm 0.05^{\mathrm{a}}$ ) but was significantly different $(\mathrm{p}<0.05)$ from that of groups which received only zinc sulfate (CZI $0.43 \pm 0.08^{\mathrm{a}}$, CZII $0.44 \pm 0.06^{\mathrm{b}}$, CZIII $0.42 \pm 0.03^{\mathrm{b}}$ ), considering each level of zinc added. Dose-response curves for femur weight as a function of dietary zinc obtained from nonlinear fits are shown in Fig. (2).

Nonlinear fit relevant parameters and relative bioavailability calculations are shown in Table $\mathbf{1}$. As can be seen, the value of the maximum effect (Ymax) achieved for weight gain and femur weight is higher for zinc gluconate stabilized with glycine in the probiotic than for the other zinc source. 


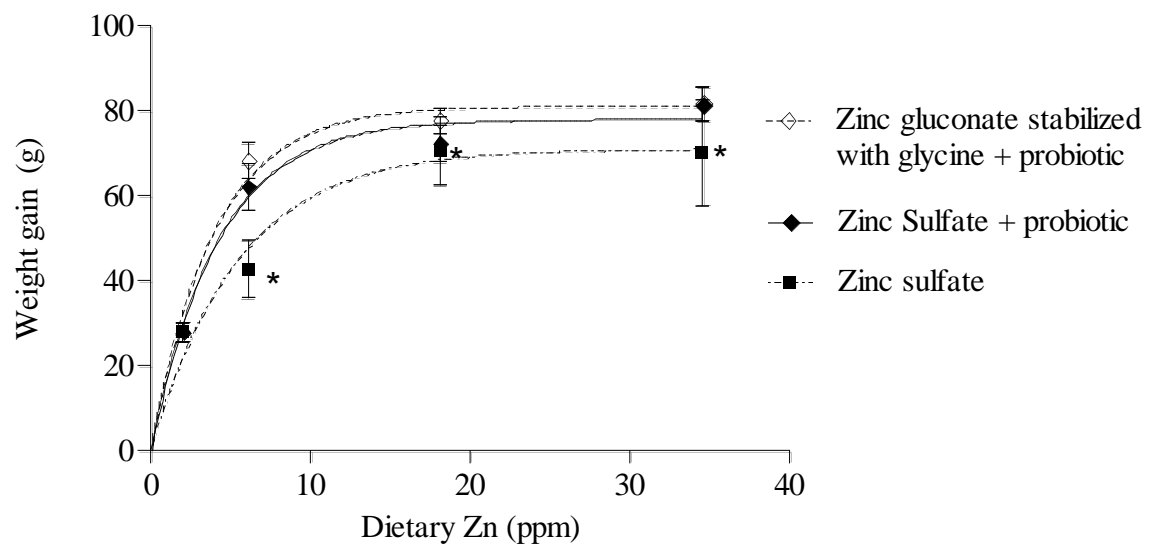

Fig. (1). Nonlinear weight gain fit as a function of zinc concentration in experimental diets for two different zinc sources: zinc sulfate and zinc gluconate stabilized with glycine. Values are shown as mean \pm SD. *indicates significant differences among different diets at the same dietary zinc concentration.

Table 1. Non Linear fit Parameters and Relative bioavailability of Zinc Sulfate + Probiotic, Zinc Gluconate Stabilized with Glycine + Probiotic and Zinc Sulfate for Weight Gain and Femur Weight

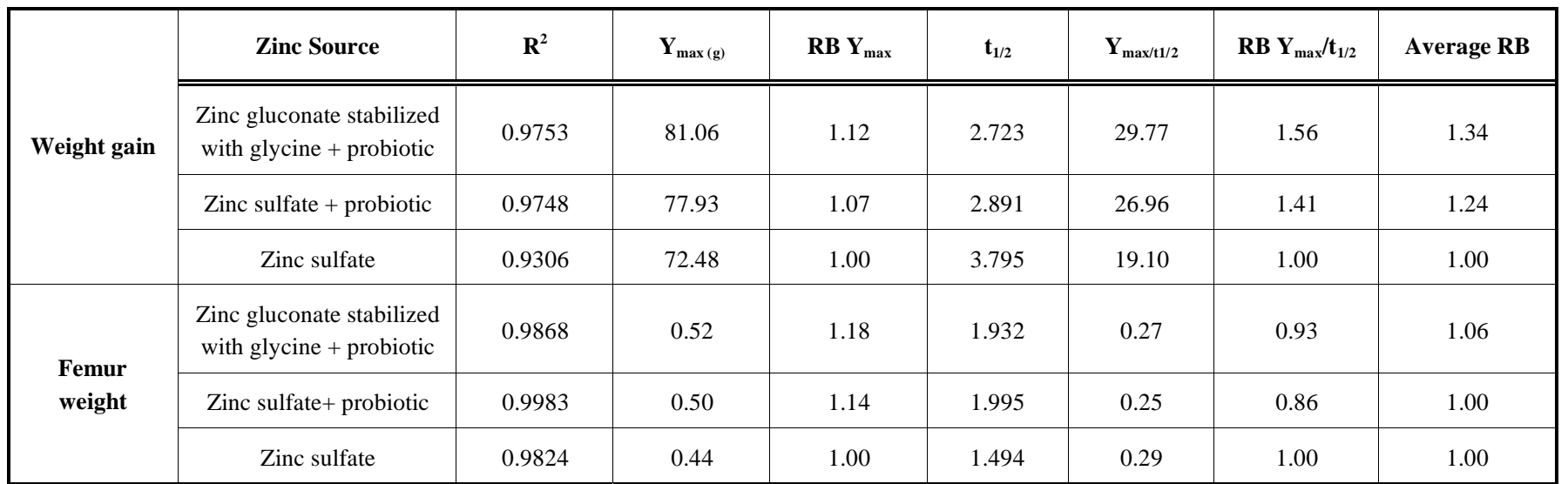

Parameters of Non Linear fit: $\mathrm{R}^{2}$, Correlation Coefficient of the Adjustment; $\mathrm{Y}_{\max }$, Maximum Response Reached; $\mathrm{T}_{1 / 2}$, Dietary Zinc Concentration Needed to Achieve Half of the Maximum Response; RB, Relative Bioavailability.

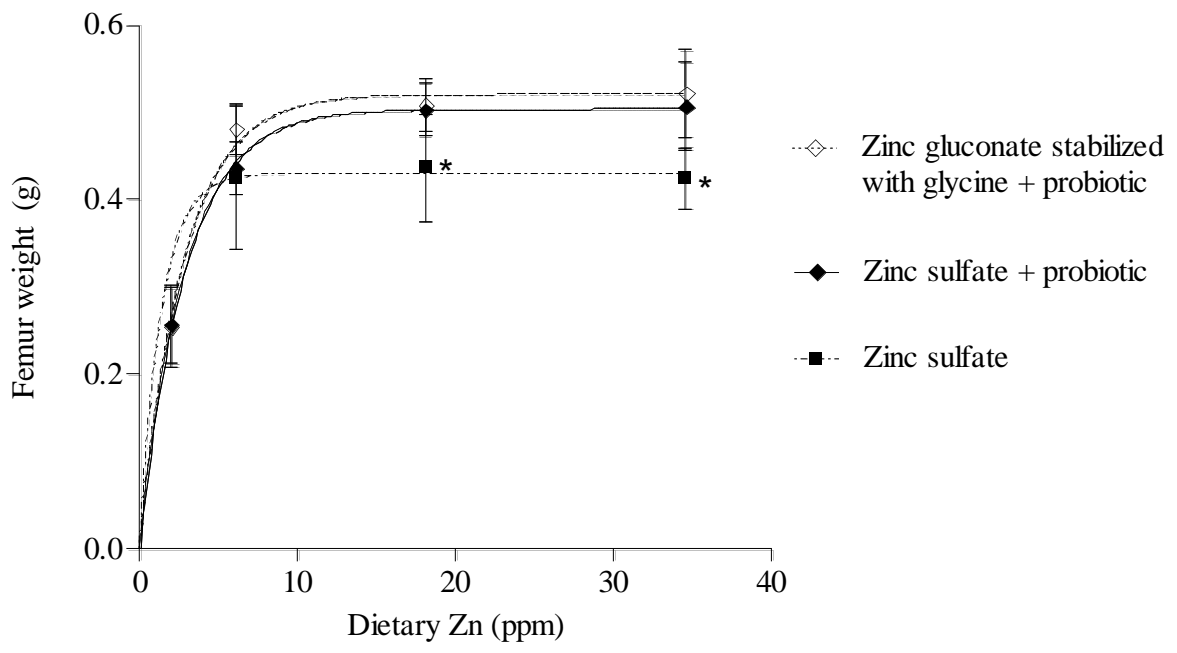

Fig. (2). Nonlinear femur weight fit as a function of zinc concentration in experimental diets for two different zinc sources: zinc sulfate and zinc gluconate stabilized with glycine. Values are shown as mean \pm SD. *indicates significant differences among different diets at the same dietary zinc concentration. 
Likewise, the dietary zinc concentration to achieve half of the maximum effect $(\mathrm{t} 1 / 2)$ is lower for zinc gluconate stabilized with glycine than for the other zinc source.

Femur zinc content (ppm) was similar for groups that were fed diets containing zinc sulfate both with and without the probiotic (SZI 43.67 $\pm 6.96^{\mathrm{a}}$, SZII 76.29 $\pm 8.01^{\mathrm{a}}$, SZIII $84.51 \pm 2.44^{\mathrm{a}}$, CZI $45.97 \pm 3.73^{\mathrm{a}}$, CZII $74.96 \pm 4.91^{\mathrm{a}}$, CZIII $84.94 \pm 2.28^{\mathrm{a}}$ ), but was significantly different $(\mathrm{p}<0.05)$ from that of groups that received zinc gluconate stabilized with glycine in the probiotic (GZI $49.70 \pm 10.78^{\mathrm{a}}$, GZII $95.29 \pm 4.32^{\mathrm{b}}$, GZIII $97.04 \pm 8.40^{\mathrm{b}}$ ), starting with a zinc level of $18 \mathrm{ppm}$ (for each level with the same provision of zinc, different superscripts mean that they are significantly different). Dose-response linear regression fit for femur zinc content is shown in Fig. (3). A slope ratio was used to determine relative bioavailability of zinc, as shown in Table 2 . In this case, the parameters evaluated as Y-intersection and slope demonstrate that the effect of glycine-stabilized zinc gluconate in a probiotic on bone zinc deposition is higher than that of the other zinc source.

\section{Proliferation}

Selective mitogen-induced $\mathrm{T}$ cell proliferative response was studied in lymphocytes. Due to the well-known lym- phoid profile, cell suspensions from lymph nodes were used for the T-selective mitogen ConA stimulation. As can be seen in Fig. (4), the groups that received glycine-stabilized zinc gluconate (GZIII) in the probiotic displayed significantly higher $\left[{ }^{3} \mathrm{H}\right] \mathrm{TdR}$ incorporation $(\mathrm{P}<0.05)$ than those receiving zinc sulfate in the probiotic (SZIII) and the group receiving a balanced diet. However, the balanced diet provided the highest zinc concentration. In addition, these latter two groups exhibited a similar proliferation index.

\section{Antioxidant Power Assay}

The results for the total antioxidant capacity of serum measured by means of the DPPH assay are shown in Fig. (5). Antioxidant power tends to increase with the provision of zinc in the diet, independently of the zinc source provided. In some cases, differences were statistically significant $(\mathrm{P}<0.05)$. However, it seems that antioxidant power is higher when a probiotic is not provided $(\mathrm{P}<0.05)$.

The antioxidant capacity related to the ascorbic acid status in serum was evaluated by means of the TEMPO assay Fig. (6). In this case, antioxidant power was similar for all dietary zinc levels independent of the zinc source, although glycine-stabilized zinc gluconate provided with the probiotic rendered significantly higher values $(\mathrm{P}<0.05)$.

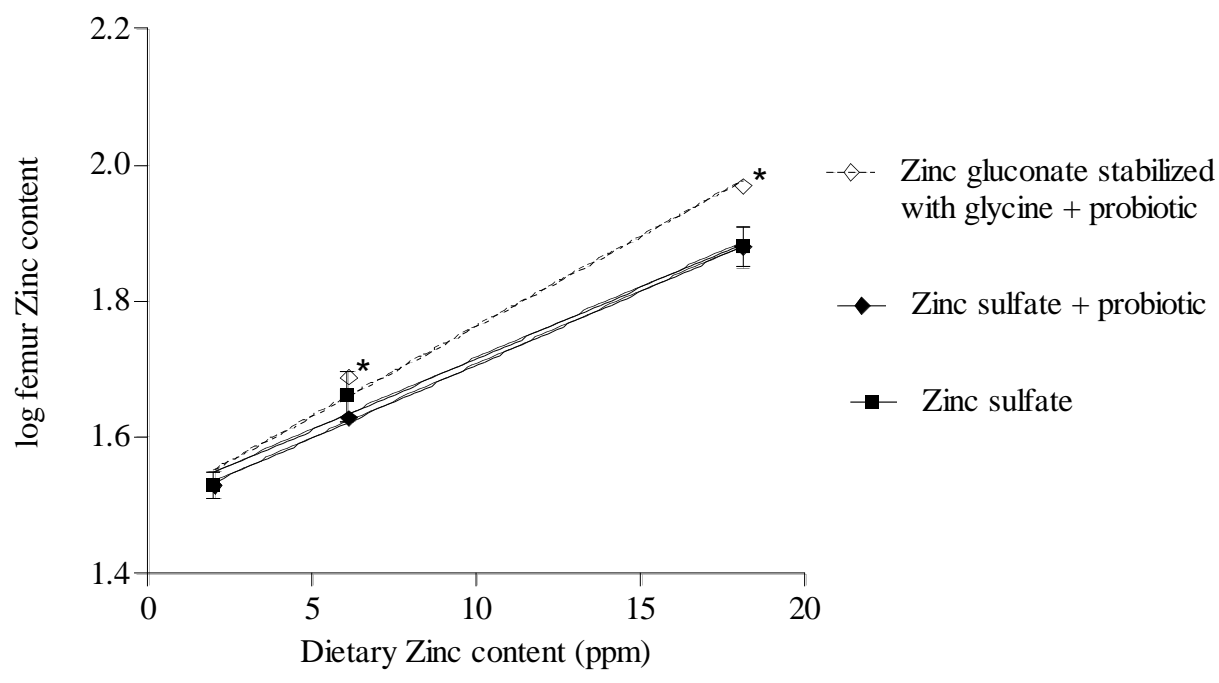

Fig. (3). Linear regression fit for log femur zinc content as a function of zinc dietary concentration in experimental diets for three different zinc sources: zinc sulfate + probiotic, zinc gluconate stabilized with glycine + probiotic and zinc sulfate. Values are shown as mean \pm SD. *indicates significant differences among different diets at the same dietary zinc concentraiton.

Table 2. Linear Regression Fit Parameters and Relative Bioavailability of Zinc Sulfate + Probiotic, Zinc Gluconate Stabilized with Glycine + Probiotic and Zinc Sulfate for Femur Zinc Content

\begin{tabular}{|c|c|c|c|c|c|}
\hline \multirow{4}{*}{$\begin{array}{c}\text { Femur zinc } \\
\text { content }\end{array}$} & Zinc Source & $\mathbf{R}^{2}$ & Y Intersection (ppm) & Slope & RB \\
\hline & Zinc sulfate + probiotic & 0.9989 & $1.492 \pm 0.008$ & $0.022 \pm 0.001$ & 1.05 \\
\hline & $\begin{array}{l}\text { Zinc gluconate stabilized with } \\
\text { glycine + probiotic }\end{array}$ & 0.9857 & $1.499 \pm 0.035$ & $0.026 \pm 0.003$ & 1.24 \\
\hline & Zinc sulfate & 0.9835 & $1.507 \pm 0.030$ & $0.021 \pm 0.002$ & 1.00 \\
\hline
\end{tabular}

Parameters of Linear Regression fit: $\mathrm{R}^{2}$ Correlation Coefficient of Adjustment; Y Intersection; Slope; RB Relative Bioavailability. 


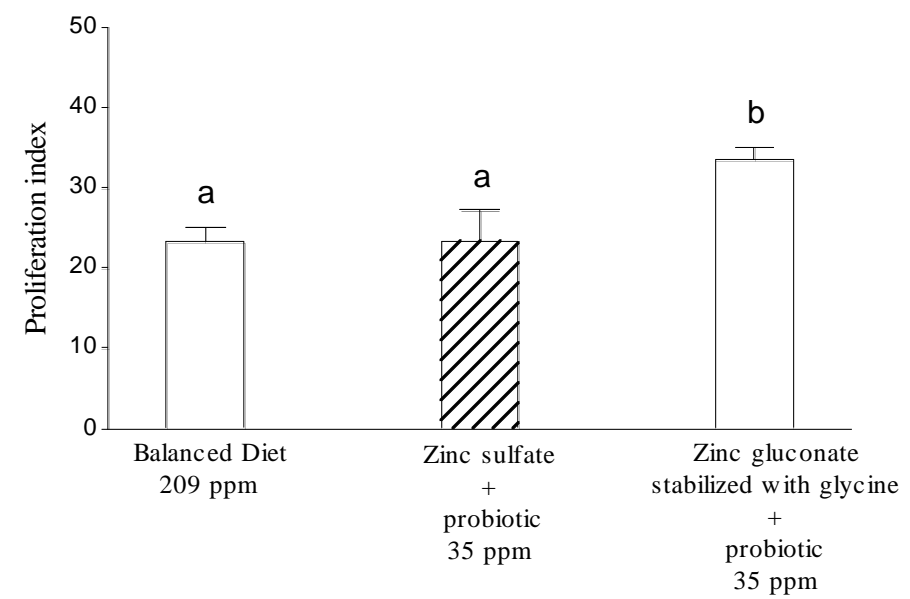

Fig. (4). Mitogen-induced T cell proliferative response with optimal ConA concentration for groups receiving zinc sulfate and zinc gluconate stabilized with glycine both provided in the probiotic at $35_{\mathrm{ppm}}$. Proliferation index was calculated as a ratio between proliferation observed with mithogen/basal proliferation. Results are shown as mean $\pm \mathrm{SD}$. $* \mathrm{P}<0.05$.

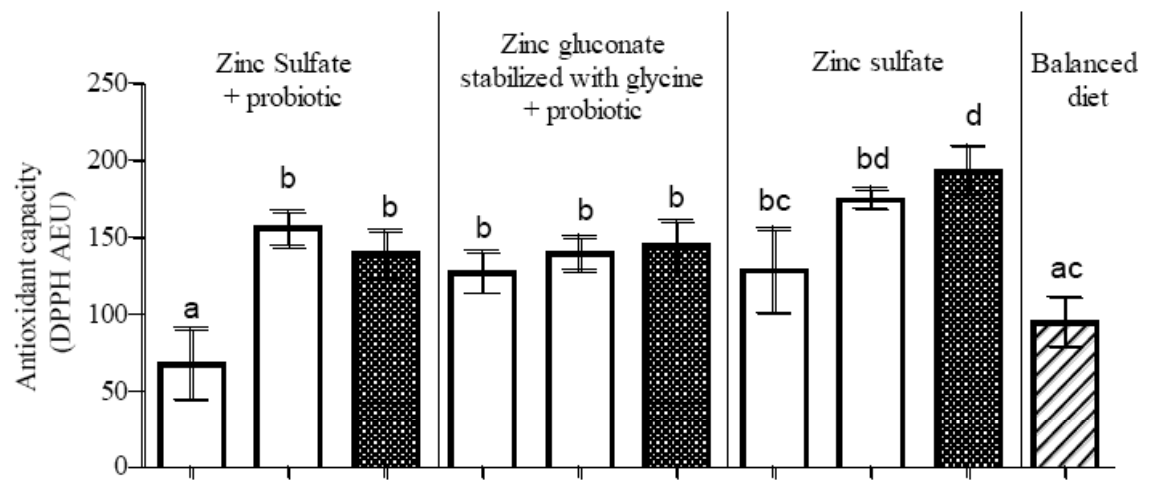

6ppm $\quad 18 \mathrm{ppm} \quad 35 \mathrm{ppm} \quad 6 \mathrm{ppm} \quad 18 \mathrm{ppm} \quad 35 \mathrm{ppm} \quad 6 \mathrm{ppm} \quad 18 \mathrm{ppm} \quad 35 \mathrm{ppm}$ 209ppm

Fig. (5). Antioxidant capacity measured by means of DPPH assay for groups recieving zinc sulfate + probiotic, zinc gluconate stabilized with glycine + probiotic and zinc sulfate at different zinc dietary concentrations and a commercial balancecd diet. AEU: Ascorbic equivalent units. Results are shown as mean \pm SD and bars not sharing a superscript are significantly different.

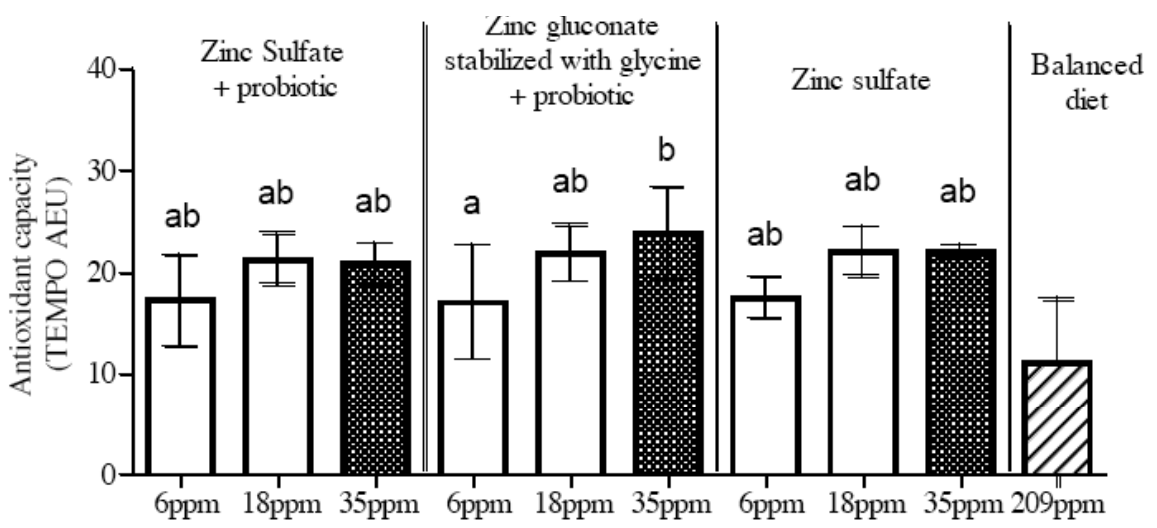

Fig. (6). Anitoxidant capacity measured by mean of TEMPO assay for zinc sulfate + probiotic, zinc gluconate stabilized with glycine + probiotic and zinc sulfate at different zinc dietary concentrations. AEU: Ascorbic equivalent units. Results are shown as as mean \pm SD and bars not sharing a superscript are significantly different.

\section{DISCUSSION AND CONCLUSION}

Food fortification, which refers to the addition of micronutrients to processed foods, is a very cost effective strategy that can lead to relatively rapid improvements in the micro- nutrient status of a population. An obvious requirement is that the fortified food needs to be consumed in adequate amounts by the target population. It is also necessary to have access to and to use compounds that are easily absorbed and 
that do not affect the sensory properties of foods. For this reason, fermented milk is a very interesting vehicle for fortification. The association of zinc with a probiotic appears to be a rational combination to improve some health benefits that are commonly claimed for each one. Zinc compounds that are suitable for use as food fortificants include sulfate, chloride, gluconate, oxide and stearate. All of these compounds are either white or colorless but have varying water solubilities; some have an unpleasant taste when added to certain foods. The effects of added zinc on the sensory properties of foods should be tested in the combination of vehicle-fortificant at fortification levels. Zinc sulfate is very reactive to the nutritional matrix and changes the color and taste of several foods, whereas zinc gluconate stabilized with glycine is less reactive and colorless and thus more suitable to be used in technological processes of industrial food fortification. The present study described a bioavailability assay to evaluate two zinc compounds as candidates for zinc fortification of fermented milk in combination with a probiotic such as Lactobacillus casei (DN114001). These zinc compounds were zinc sulfate as a reference standard and glycinestabilized zinc gluconate as the alternative. The results obtained indicate that the presence of the probiotic does not interfere with zinc bioavailability of zinc sulfate. Indeed, it appears that the probiotic enhances zinc bioavailability though the mechanism by which this is achieved is yet unknown and should be studied in further investigations. Likewise, zinc gluconate stabilized with glycine combined with a probiotic has similar bioavailability compared to zinc sulfate. From analysis of the effects of these two zinc sources, it is clear that the combination of the probiotic and zinc gluconate stabilized with glycine is superior to zinc sulfate, with or without probiotic. Weight gain, femur weight and femur zinc content, all indicators of growth and bone development, were favored by the combination of glycine-stabilized zinc gluconate and a probiotic. Those results were reinforced with two additional assays evaluating important effects of zinc and probiotics. The first one was the antioxidant power assay. Zinc has been reported to play an important role in the redox state as an indirect antioxidant promoter [8]. Oxidative stress developed as a consequence of even mild zinc deficiency has been related to aging and impaired immune function, DNA repair and DNA binding of some regulatory proteins such as p53. To prevent these negative consequences, consumption of a nutritious food containing antioxidants that have been proven effective is an interesting option. Even though probiotics have not been considered as antioxidants, zinc has, so due to the consequences of redox unbalances, we evaluated the antioxidant capacity of both zinc sources in fermented milk with added probiotic. From the DPPH and TEMPO scavenging assays, total antioxidant capacity and ascorbicrelated antioxidant capacity were similar for all treatments, but a tendency for capacity to increase at a higher zinc dietary concentration was observed. Likewise, an improvement of this effect in the absence of the probiotic was observed, but the values were too similar to be conclusive. In both cases, all treatments showed higher AEU than for that of the balanced diet. Our results clearly demonstrate that it is not only the amount of the mineral that is relevant to physiological effects, but also the bioavailability of the mineral and thus its chemical form. The zinc source of the balanced diet is unknown, but it can be speculated that zinc has less bioavailability in this diet than in the ones evaluated, or that other components present in the balanced diet negatively interfere with zinc absorption.

Finally, immune function was preliminarily evaluated as $\mathrm{T}$ cell-mediated immunity. A higher response was observed for zinc provided as zinc gluconate stabilized with glycine with the probiotic compared to zinc provided as zinc sulfate in the same nutritional matrix or in the balanced diet. Further research is needed and will be performed in order to achieve more conclusive results on this subject.

In conclusion, the theoretical combination of two beneficial nutritional components has satisfying results, not only from the point of view of bioavailability of the mineral source, but also on its practical use, improvement of immunological function, growth and bone development.

\section{ACKNOWLEDGEMENTS}

This study was funded by the University of Buenos Aires (UBACYT B007 grant).

\section{ABBREVIATIONS}

$\begin{array}{ll}\mathrm{AEU} & =\text { Ascorbic equivalent units } \\ \mathrm{dpm} & =\text { Disintegrations per minute } \\ \mathrm{d} & =\text { Days } \\ \mathrm{ESR} & =\text { Electron spin resonance } \\ \mathrm{g} & =\text { Grams } \\ \mathrm{h} & =\text { Hours } \\ {\left[{ }^{3} \mathrm{H}\right] \mathrm{TdR}} & =\left[{ }^{3} \mathrm{H}\right] \text {-thymidine } \\ \mathrm{Khz} & =\text { Kilohertz } \\ \mathrm{min} & =\text { Minutes } \\ \mathrm{ppm} & =\text { Parts per million }\end{array}$

\section{REFERENCES}

[1] Brandão-Neto V, Stefan V, Mendoça BB, Bloise W, Castro A V. The essential role of zinc in growth. Nutr Res 1995; 15: 335-58.

[2] Prasad AS. Discovery and importance of zinc in human nutrition. Fed Proc 1984; 43: 2829-34.

[3] Tuerk MJ, Fazel N. Zinc deficiency. Curr Opin Gastroenterol 2009; 25: 136-43.

[4] Barnett JB, Hamer DH, Meydani SN. Low zinc status: a new risk factor for pneumonia in the elderly? Nutr Rev 2009; 68(1): 30-7.

[5] Black RE. Therapeutic and preventive effects of zinc on serious childhood infectious deseases in developing countries. Am J Clin Nutr 1998; 68: 476S-9S.

[6] Black RE, Sazawal S. Zinc and childhood infectious disease morbidity and mortality. Br J Nutr 2001; 85(2): S125-S9.

[7] Salvatore SS, Hauser B, Devreker T, et al. Probiotics and zinc in acute infectious gastroenteritis in children: are they effective? Nutr 2007; 23: 498-506.

[8] Wolfgang M. Metallothionein redox biology in the cytoprotective and cytotoxic functions of zinc. Exp Gerontol 2007; 43: 363-9.

[9] Prasad AS, Beck FWJ, Bao B, et al. Zinc supplementarion decreases incidence of infections in the elderly: effect of zinc on generation of cytokines and oxidative stress. Am J Clin Nutr 2007; 85: 837-44.

[10] Prasad AS. Clinical, immunological, anti-inflammatory and antioxidant roles of zinc. Exp Gerontol 2007; 43: 370-7.

[11] Song Y, Leonard SW, Traber MG, Ho E. Zinc deficiency affects DNA damage, oxidative stress, antioxidant defenses, and DNA repair in rats. J Nutr 2009; 139: 1626-31. 
[12] Ho E, Ames BN. Low intracellular zinc induces oxidative DNA damage, disrupts p53, NFKB, and AP1 DNA binding, and affects DNA repair in a rat glioma cell line. Proc Natl Acad Sci USA 2002; 26: 16770-5.

[13] Brown KH, Hess SY, eds. Assessment of the risk of zinc deficiency in populations and options for its control. International Zinc Nutrition Consultative Group (IZiNCG). Food Nutr Bull 2009; 25: S5-S179.

[14] Hotz C, Brown KH, eds. Assessment of the risk of zinc deficiency in populations and options for its control. International Zinc Nutrition Consultative Group (IZiNCG). Food Nutr Bull 2004; 25: S91S202.

[15] Hamilton-Miller JMT. Probiotics and prebiotics in the elderly. Postgrad Med J 2004; 80: 447-51.

[16] Rolfe RD. The role of Probiotic Cultures in the control of Gastrointestinal Health. Symposium: Probiotic Bacteria: Impplication for Human Health. J Nutr 2000; 130: 396S-402S.

[17] Baken KA, Ezendam J, Gremmer ER, et al. Evaluation of immunomodulation by Lactobacillus casei Shirota: Immune function, auotoimmunity and gene expression. Int J Food Microbiol 2006; 112: 8-18.

[18] Gill H, Prasad J. Probiotics, immunomodulation, and health benefits. Adv Exp Med Biol 2008; 606: 423-54.

[19] Hemsworth J, Hekmat S, Reid G. The development of micronutrient supplemented probiotic yogurt for people living with HIV: Laboratory testing and sensory evaluation. Innovative Food Sci Emerging Technol 2011; 12(1): 79-84.

[20] Ren Z, Zhao Z, Wang Y, Huang K. Preparation of selenium/zincenriched probiotics and their effect on blood selenium and zinc concentrations, antioxidant capacities, and intestinal microflora in canine. Biol Trace Elem Res 2010; Epub ahead of print.

[21] Isa L, Lucchini A, Lodi S, Giachetti M. Blood zinc status and zinc treatment in human immunodeficiency virus-infected patients. Int J Clin Lab Res 1992; 22(1): 45-7.

[22] Mocchegiani E, Muzzioli M. Therapeutic application of zinc in human immunodeficiency virus against opportunistic infections. J Nutr 2000; 130: 1424S-31S.

[23] Irvine SL, Hummelen R, Hekmat S, Looman CW, Habbema JD, Reid G. Probiotic yogurt consumption is associated with an increase of CD4 count among people living with HIV/AIDS. J Clin Gastroenterol 2010; 44(9): e201-5.
[24] Anukam KC, Osazuwa EO, Osadolor HB, Bruce AW, Reid G. Yogurt containing probiotic Lactobacillus rhamnosus GR-1 and L. reuteri $\mathrm{RC}-14$ helps resolve moderate diarrhea and increases CD4 count in HIV/AIDS patients. J Clin Gastroenterol 2008; 42(3): 239-43.

[25] Trois L, Cardoso EM, Miura E. Use of probiotics in HIV-infected children: a randomized double-blind controlled study. J Trop Pediatr 2008; 54(1): 19-24.

[26] Franz KB, Kennedy BM, Fellers DA. Relative bioavailability of zinc using weight gain of rats. J Nutr 1980; 110: 2263-71.

[27] Franz KB, Kennedy BM, Fellers DA. Relative bioavailability of zinc from selected cereals and legumes using rat growth. J Nutr 1980; 110: 2272-83.

[28] Mercer LP, Flodin NW, Morgan PH. New methods for comparing the biological efficiency of alternate nutrient sources. J Nutr 1978; 108: $1244-9$.

[29] O'Dell BL, Burpo CE, Savage JE. Evaluation of zinc availability in foodstuffs of plant and animal origin. J Nutr 1972; 102: 653-60.

[30] Salgueiro J, Leonardi N, Zubillaga M, et al. Determination of relative bioavailability of zinc in a petit suisse cheese using weight gain and bone zinc content in rats as markers. Biol Trace Elem Res 2005; 104: 261-7.

[31] Tesán FC, Collia N, Arnoldi S, et al. Relative bioavailability of zinc in yogurt using weight gain, femur weight and bone zinc content in rats as markers. Open Nutra J 2009; 2: 16-19.

[32] Reeves PG, Nielsen FH, Fahey GC. AIN-93 purified diets for laboratory rodents: final report of the American Institute of Nutrition ad hoc Writing Committee on the Reformulation of the AIN-76 Rodent Diet. J Nutr 1993; 123: 1939-51.

[33] Lysionek AE, Zubillaga MB, Calmanovici GP, et al. Modification of the ferrozine technique to analyze iron contents in different foods. Biol Trace Elem Res 1998; 65: 87-94.

[34] Brand-Williams W, Cuvelier ME, Berset C. Use of free radical method to evaluate antioxidant activity. LWT-Food Sci Technol 1995; 28(1): 25-30.

[35] Piehl LL, Facorro GB, Huarte MG, et al. Plasmatic antioxidant capacity due to ascorbate using TEMPO scavenging and electron spin resonance. Clin Chim Acta 2005; 359: 78-88.

[36] Sokal RR, Rohlf FJ. Biometry. Freeman WH, Ed. San Francisco: 1996. 